\title{
Fatou Diome, Impossible de grandir
}

\section{Carminella Biondi}

\section{(2) OpenEdition}

\section{Journals}

\section{Edizione digitale}

URL: http://journals.openedition.org/studifrancesi/2311

DOI: 10.4000/studifrancesi.2311

ISSN: 2427-5856

\section{Editore}

Rosenberg \& Sellier

\section{Edizione cartacea}

Data di pubblicazione: 1 aprile 2014

Paginazione: 194-195

ISSN: 0039-2944

\section{Notizia bibliografica digitale}

Carminella Biondi, « Fatou Diome, Impossible de grandir », Studi Francesi [Online], 172 (LVIII | I) | 2014

online dal 01 avril 2014, consultato il 18 septembre 2020. URL : http://journals.openedition.org/ studifrancesi/2311; DOI : https://doi.org/10.4000/studifrancesi.2311

\section{Questo documento è stato generato automaticamente il 18 settembre 2020.}

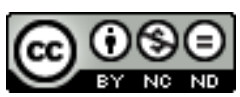

Studi Francesi è distribuita con Licenza Creative Commons Attribuzione - Non commerciale - Non opere derivate 4.0 Internazionale. 


\title{
Fatou Diome, Impossible de grandir
}

\author{
Carminella Biondi
}

\section{NOTIZIA}

FATOU DIOME, Impossible de grandir, Paris, Flammarion, 2013, pp. 406.

1 La narratrice non nasconde l'obiettivo del suo racconto, anche se non lo enuncia in apertura del romanzo: «Je n'écris pas pour plaire [...]. J'écris pour tremper ma plume dans les plaies béantes [...]. J'écris pour regarder la vie en face [...]. J'écris pour toutes les femmes qu'on a forcées à se marier...», ecc. (p. 310). Ma soprattutto: «'écris pour tous les bâtards du monde qui se font insulter, torturer et mépriser...» (p. 311). Arriviamo così al cuore della storia della narratrice, Salie, (un nome che porta il marchio della vergogna), che comincia con un'ossessione inspiegabile, apparentemente banale, ma così forte da creare uno stato di malessere permanente e da portare la protagonista al pronto soccorso, quando l'evento oggetto di tale ossessione non può più essere rinviato. Salie pranza volentieri con gli amici, purché non l'invitino a casa loro, perché questo costituisce per lei un ostacolo insormontabile. Quando tutte le vie di fuga per sottrarsi all'invito sono state inutilmente esperite, la protagonista, in attesa dell'infausto evento, entra in uno stato di malessere, addirittura di angoscia, che viene indagato e raccontato con minuzia maniacale e feroce nel corso di pagine e pagine di un monologo disperato, che farà riaffiorare, come in una seduta psicanalitica, brandelli del lontano passato in Africa (Salie, come la scrittrice, vive ora a Strasburgo) rivissuti con grande sofferenza e grande difficoltà; anche il lettore fatica a ricomporre una storia dolorosa (sia pure non del tutto priva di risvolti felici) che spiega la strana, ossessiva ripulsa di fronte alla richiesta di sedere a una tavola in casa di amici, ripulsa che è soltanto il punto più sensibile e dolente di una più generale misantropia: «Car, en réalité, je m'en voulais de ne pas savoir participer au ballet social» (p. 80).

2 Ho parlato di monologo, ma questo non è il solo strumento espressivo che permette alla narratrice di gettare la sonda negli abissi della propria vita interiore, perché alla Salie adulta si affianca la presenza costante, e irriverente, della Salie bambina, che impone 
un dialogo difficile non solo fra il tempo presente e quello passato, ma anche fra due mondi: Strasburgo e il villaggio di Niodior, in Africa, dove Salie è nata ed ha vissuto a lungo. La "gamine", o la "petite" come viene chiamata nel romanzo, non lascia tregua, mette l'adulta con le spalle al muro e la costringe, spesso a forza, ad un viaggio a ritroso, doloroso e salvifico ad un tempo: «Une petite fille me poursuit, me harcèle, m'assiège; après tant d'années de lutte je ne peux toujours rien contre ses assauts; parfois croyant agir à ma guise, je découvre avec stupeur que je ne fais que succomber à ses humeurs: grandir semble impossible» (p. 396). Alla fine Salie scoprirà che è bello conservare dentro di sé una bambina che non è condizionata dalle convenzioni sociali e smetterà di respingerla come una seccatrice importuna: «J'avais pris la résolution de faire définitivement la paix avec la Petite et de ne plus jamais me faufiler dans un moule de circonstance, conçu par d'autres» (p. 404).

Ma per arrivare a questa presa di coscienza che le permette, forse, di non vivere più in uno stato di inadeguatezza permanente, e quindi di colpa, il cammino è stato davvero lungo; lo scavo nel passato, molto doloroso, ha portato alla luce l'origine lontana del male, la nascita bastarda, che ha fatto di lei «la fille du péché», «l'enfant du diable» (p. 40), con tutto il corollario che ciò ha portato con sé nel piccolo villaggio natale: disprezzo, sfruttamento da parte dei parenti, in particolare da parte del fratello della madre (che si rivelerà un vero pescecane e che sarà nel romanzo il bersaglio delle frecce più avvelenate), ma anche (ed è questo l'aspetto più doloroso) distacco dalla madre stessa, a cui il matrimonio con un uomo che non è il padre di Salie toglie ogni libertà e impone una presa di distanza dal proprio passato. Fanno da contrappeso a tutto questo l'amore e la saggezza dei nonni materni, ma evidentemente i piatti della bilancia non sono in equilibrio se lunghi anni di vita e di successi non sono bastati per far dimenticare a Salie di essere stata une «bouche illégitime», alla quale viene rifiutato di sedersi a tavola. Non dimenticherà mai le parole della nonna che fa di tutto per tenerla lontana da situazioni che potrebbero divenire umilianti per lei: «Le plus simple: tu ne manges que chez nous, ainsi, tu ne dérangeras personne [...] n'accepte jamais qu'on t'humilie pour de la nourriture!» (p. 48). Ecco spiegata l'angoscia incontrollabile e lo stato penoso di «asphyxie» (p. 156) che scatena in lei un semplice invito a cena in casa di amici: è ancora la «bouche illégitime» che non ha diritto ad un posto a tavola in casa d'altri. Tutte le sensazioni forti che ruotano attorno a questa infanzia di dolore e di umiliazione ancora prepotentemente presente nella vita dell'adulta (la "gamine" non le dà requie) sono espresse in una lingua incendiaria, talvolta urticante ("Confier une blessure, c'est aussi blesser», p. 200), ma anche commossa, che travolge il lettore e lo costringe a immergersi, per un verso, negli abissi di una coscienza straziata che anela alla pace e, per altro verso, nella realtà cruda di un'Africa in via di trasformazione, in cui ai vecchi pregiudizi vengono ad affiancarsi i nuovi, più subdoli e più ridicoli, di una società "occidentalizzata". Il ritmo del racconto e la scansione delle frasi sono incalzanti: «l'essentiel, c'est de ne pas être celui par qui le mouvement s'arrête» (p. 227) e sembrano non voler lasciare tregua né alla narratrice (Yo sólo quiero caminar è la colonna musicale della storia) né al lettore. Come aveva già fatto Marguerite Yourcenar (in Feux ma anche in quasi tutti gli scritti giovanili) per dire una passione incontrollabile e nello stesso tempo arginarne l'irruenza, e quindi esercitare un controllo, la narratrice fa un ricorso massiccio all'uso di massime che, nel suo caso, derivano dalla saggezza imparata dai nonni e che, nell'economia del racconto, hanno la funzione di creare una pausa al ritmo travolgente prodotto dall'ansia della narratrice: l'esperienza individuale è così ricondotta ad una dimensione più generale in cui 
trovano voce tutti gli umiliati e gli assetati di giustizia. La bambina, con cui ha accettato infine di convivere in pace, è lì per indicare il cammino «Une petite fille m'accompagne et m'apprend à vivre. Quand je m'essouffle à chanter Yo sólo quiero caminar, elle me prend par la main et m'explique sa méthode de marche...» (p. 406). 